\title{
Clinical and molecular cytogenetic analyses of four patients with imbalanced translocations
}

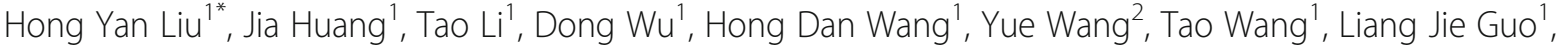 \\ Qian Nan Guo', Fei Fei Huang ${ }^{1}$, Rui Li Wang ${ }^{3}$ and Ying Tai Wang ${ }^{1}$
}

\begin{abstract}
Background: Chromosomal abnormalities that result in genomic imbalances are main causes of congenital and developmental anomalies including intellectual disability and multiple congenital malformations. In this report we describe four patients from three families with imbalanced translocations. Only a small percentage of imbalanced translocation individuals can be born to live, most of them were aborted in embryonic period. It is of great significances to precisely analysis the chromosome variation to study the relationship between genotype and phenotype.

Results: Four patients showed common clinical manifestations including delayed growth, intellectual disability, language barrier and facial dysmorphisms. In addition to the above features, lower limbs dysplasia and both foot eversion were found in patient 1, brachydactylic hand, cerebellar ataxia and congenital heart defects were also found in patient 4. Conventional karyotype analysis revealed abnormal karyotypes 46, XX, der (6) t (6: 10) (p23; q24), 46, XX, der (20) t (3; 20) (p23; p13) and 46, XX, der (22) t (3; 22) (q27; q13.3) in the four patients, respectively. Array-CGH analyses confirmed 23.6 Mb duplication on 10q25.1-q26.3 and 0.9 Mb deletions on 6p25.3, $19.9 \mathrm{Mb}$ duplication on 3p24.3-p26.3 and 0.25 Mb deletion on 20p13 and 12.5 Mb duplication on 3q27.2-q29 and 1.9 Mb deletions on 22q13.2-q13.33 in the four patients, respectively.
\end{abstract}

Conclusion: Parents with balanced translocation are passed the imbalanced chromosome to patient, and the partial monosomy and partial trisomy lead to multiple congenital malformations of four patients.

Keyword: Imbalanced translocation, Intellectual disability, Delayed growth, Language barrier, Chinese

\section{Background}

Chromosomal abnormalities that result in genomic imbalances are main cause of congenital and developmental anomalies including intellectual disability and multiple congenital malformations. The abnormal chromosomes of parents can be passed to next generation, particularly for parents carrying a balanced translocation or inversion. Balanced chromosomal translocations are often identified as a cause of infertility [1], owing to meiotic impairment can lead to gamete formation problems, in man can cause failure of spermatogenesis $[1,2]$. Research found that most breakpoint of balanced

\footnotetext{
*Correspondence: liuhongyanqhhy@126.com

'Department of Medical Genetics Institute, People's Hospital of Zhengzhou University (Henan Provincial People's Hospital), Zhengzhou 450003, Henan, China

Full list of author information is available at the end of the article
}

chromosome translocation was at or near the localization of segmental duplications which contribute to genomic instability [3], so the genetic disorders may increase of the offspring. Theoretically, for balanced translocation carriers, the chance of passing the imbalanced chromosome to child is $16 / 18$, whereas passing a normal chromosome and balanced chromosome is $1 / 18$, respectively. The former case will lead to either a spontaneous miscarriage or a live born child with intellectual disability and/or multiple congenital malformations. The reported live births rate of couple with balanced translocations ranges from 14 to $19.5 \%[4,5]$, and more than $80 \%$ of fertilized eggs were spontaneous abortion because of aneuploidy, polyploidy, imbalanced translocation and other reasons [5]. In clinic, half of these babies 
with chromosome abnormalities were inherited from a parent carrying balanced translocation or inversion [6].

Precise characterization of the chromosomal rearrangements and identification of the associated genes are important for syndrome recognition and genetic risk assessment. Array-CGH is a powerful tool for the accurate detection of genomic imbalances. It enables identification of the genes that cause mental retardation when abnormal copy numbers exist [7]. In this report we present three families with imbalanced translocation. All families had offspring with mental retardation who carried imbalanced translocation. We provided detailed analysis of the genotype-phenotype correlation and discussed possible candidate genes.

\section{Methods}

\section{Participants}

Four Patients were from three Chinese families without family history of congenital malformations. Patients showed common clinical manifestations, such as delayed growth, intellectual disability, language barrier and facial dysmorphisms. Parents of these patients went to Medical Genetics Institute for genetic consulting. Routine clinical examination was performed on four patients. Detailed birth, medical and clinical manifestations were collected after informed consent was obtained. The pedigree of three families was shown in Fig. 1.

All examinations were performed according to the guidelines of the "declaration of Helsinki". Ethical approval was obtained from the People's Hospital of Henan Provincial Ethics Committee.

\section{Karyotyping and array-CGH analyses}

Five milliliter peripheral venous blood was collected from four patients and their parents; $20 \mathrm{ml}$ amniotic fluid was collected from mother of patient 4 .

Karyotyping on GTG-banded chromosomes from patients and their parents was performed on cultured lymphocytes (patient 1 to 4 and their parents) and cultured amniocytes (family 3 II2) according to standard protocols.

To precisely determine the cytogenetic variation, a high-resolution chromosomal analysis was performed using a whole-genome oligonucleotide CGH microarray. Genomic DNA from four patients was extracted from peripheral blood lymphocytes using Qiagen blood kit (QIAGEN, Germantown, MD, USA).

Array-CGH was performed using an Agilent SurePrint G3 Human CGH Microarray Kit, 8x60K G4450A whole-genome oligonucleotide microarray (41 kb average probe spacing; $33 \mathrm{~kb}$ in Refseq genes). Digestion, ligation, PCR, Cy5-dUTP and Cy3-dUTP labeling, hybridization of test and reference DNA were performed according to the manufacturer's recommendations (Agilent Technologies, Santa Clara, California,
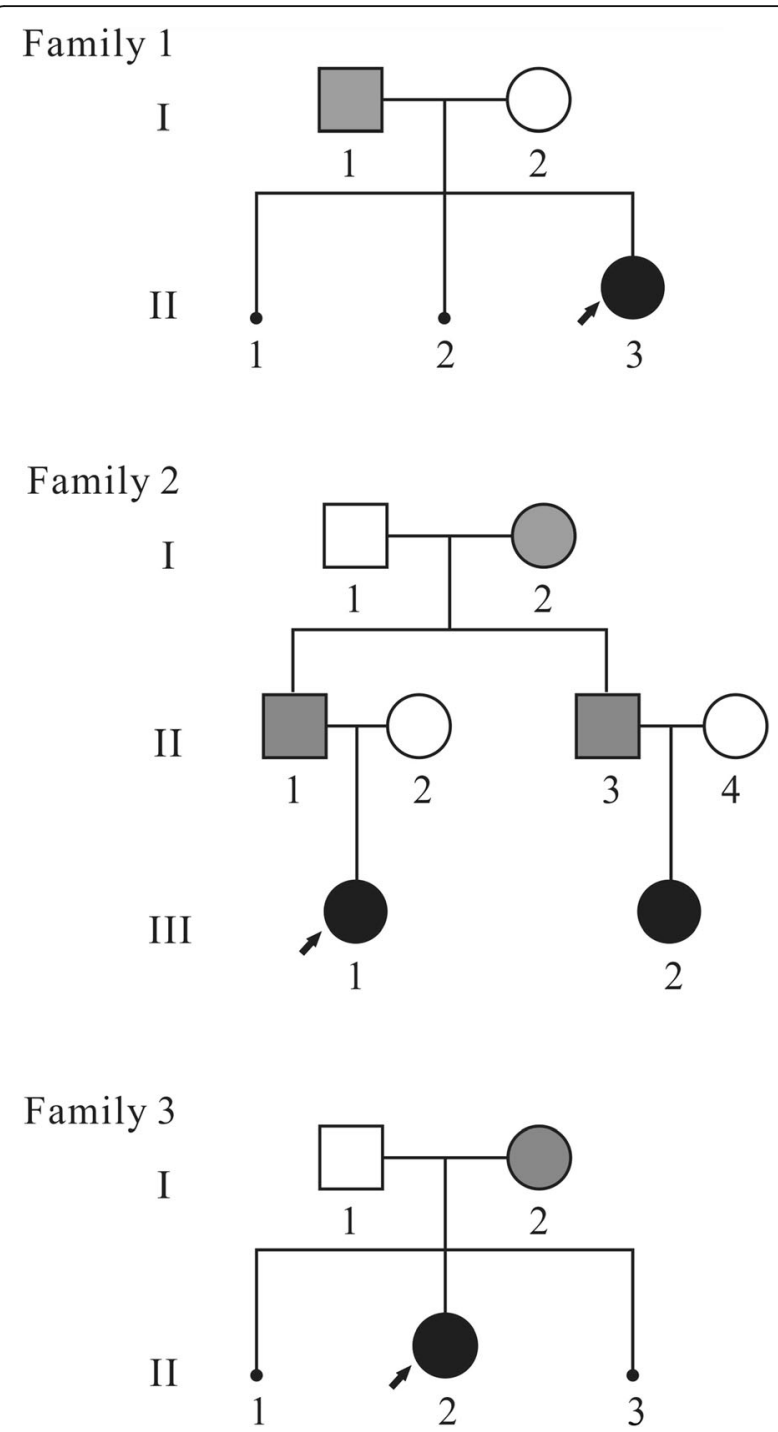

Fig. 1 Pedigree of three families reported in this study. Black symbols indicate imbalanced translocation individuals; grey symbols indicate balanced translocation individuals; black spot indicate abortion

USA). Slides were scanned using an Agilent SureScan Microarray Scanner, and analyzed using Agilent CytoGenomics 2.9. Significant copy-number changes were identified by at least three consecutive aberrant probes. Reference human genome was GRCh36/hg18.

\section{Results}

Family 1

The patient 1 (family 1: II3) is a 3 years old female. She was from the third pregnancy of healthy and nonconsanguineous young parents. Her mother had a history of two miscarriages. The physical examination revealed that patient 1 presented with multiple congenital anomalies. She had significant facial dysmorphic features, including depressed nasal bridge, anteverted nostrils, long philtrum, 
downturned angles of mouth and thin upper lips, carpshaped mouth, high arched palate, micrognathia, low set ears and low anterior hairline. Developmental evaluations showed delayed growth with short stature $(85 \mathrm{~cm},<3 \mathrm{rd}$ centile) and low weight (9.5 kg, <3rd centile). She walked without assistance at 2 years and 3 month of age, presented with walking instability. Limbs dysplasia included slim lower limbs and foot eversion on both sides. Neurological exam revealed muscular hypotonia, nerve reflex insensitivity, intellectual disability and language barrier. Feeding difficulty was present in early infancy. The patient has no history of seizure activity and congenital heart defect. Hearing, vision, and hands were normal.

The patient karyotyping was performed on peripheral blood lymphocytes. The report revealed abnormal karyotype 46, XX, der (6) t (6: 10) (p23; q24) (Fig. 2a). A similar protocol was followed for her parents' chromosome preparation. The report revealed normal mother with 46, XX pattern, but the father had balanced translocation with $46, \mathrm{XY}, \mathrm{t}(6 ; 10)$ (p23; q24) pattern. This chromosomal abnormality was a balanced translocation between 6 and 10 (Fig. 2b).

Array-CGH analysis was performed on lymphocytes DNA of this patient and detected a $23.6 \mathrm{Mb}$ duplication at 10q25.1-q26.3 (chr10:111770926-135404523) and a $0.9 \mathrm{Mb}$ deletion at 6p25.3 (chr6:170426-1106808) (Fig. 3a).

\section{Family 2}

In this family, two female cousins (patient 2 and 3) were found with delayed growth, intellectual disability and language barrier. Although with normal weight, their heights were lower than peers. The older cousin (patient 2), a 9 years old girl, also showed facial dysmorphic features, including depressed nasal bridge, ocular hypertelorism, broad nose, thin upper lip, round face with full cheeks and facial expression impairment. She could express some simple language, and have learning difficulties. She had normal motor system with good coordination and could play freely. The patient 2 had no history of seizures and cardiomyopathy. She had normal hearing and vision, as well as normal finger nails. The younger cousin (patient 3 ), a 4 years old girl, has facial dysmorphic features, including open mouth, thin upper lip and facial expression impairment. She could not speak any meaningful words. Other clinical manifestations were same as her older cousin.

Conventional karyotype analysis showed that two female cousins carried 46, XX, der (20) t (3; 20) (p23; p13) (Fig. 2c and d). The old cousin parents accepted the subsequent karyotyping with the report revealing normal 46, XX pattern of her mother, but the father had balanced translocation 46, XY, t (3; 20) (p23; p13) (Fig. 2e). The younger cousin parents and grandmother were also

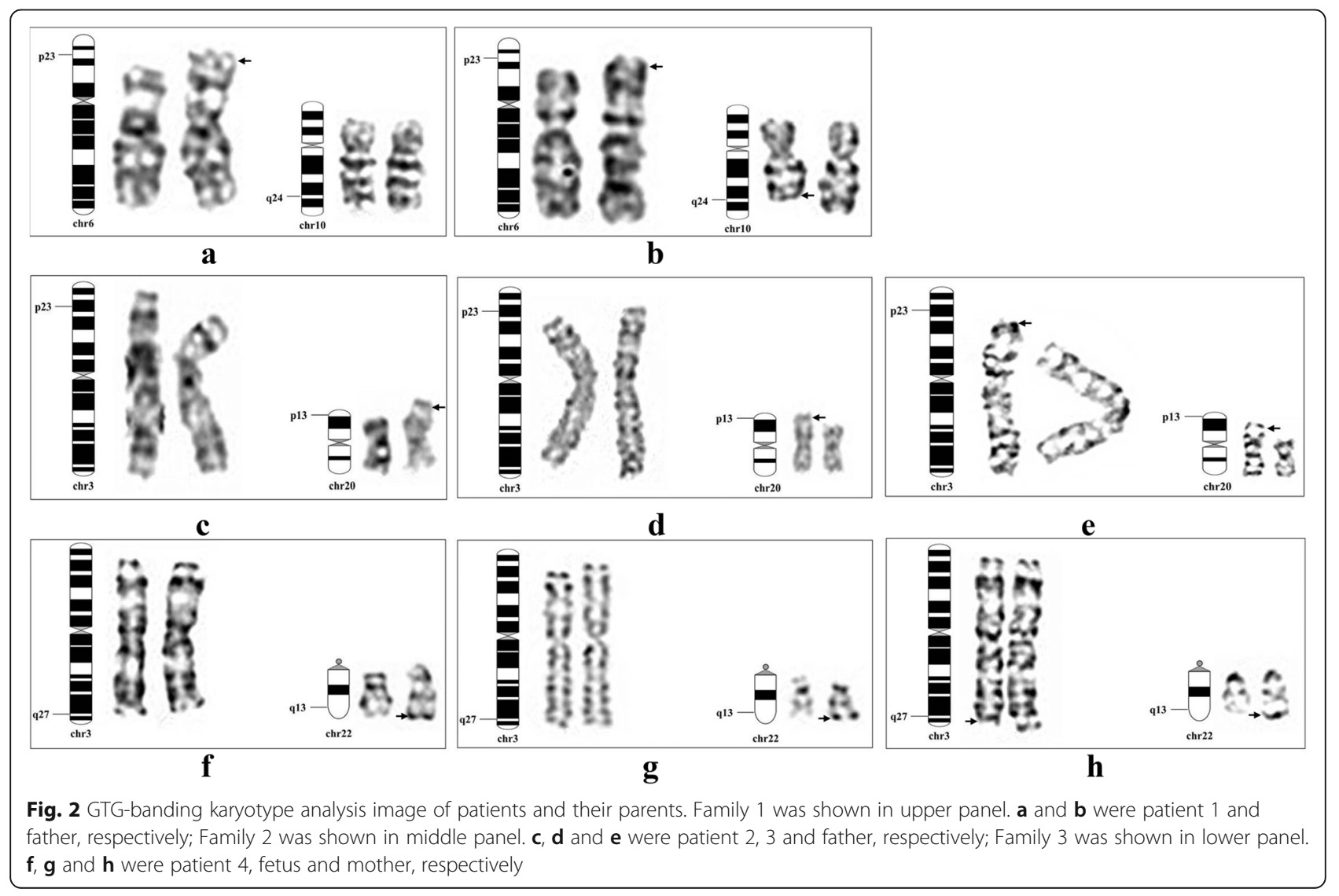




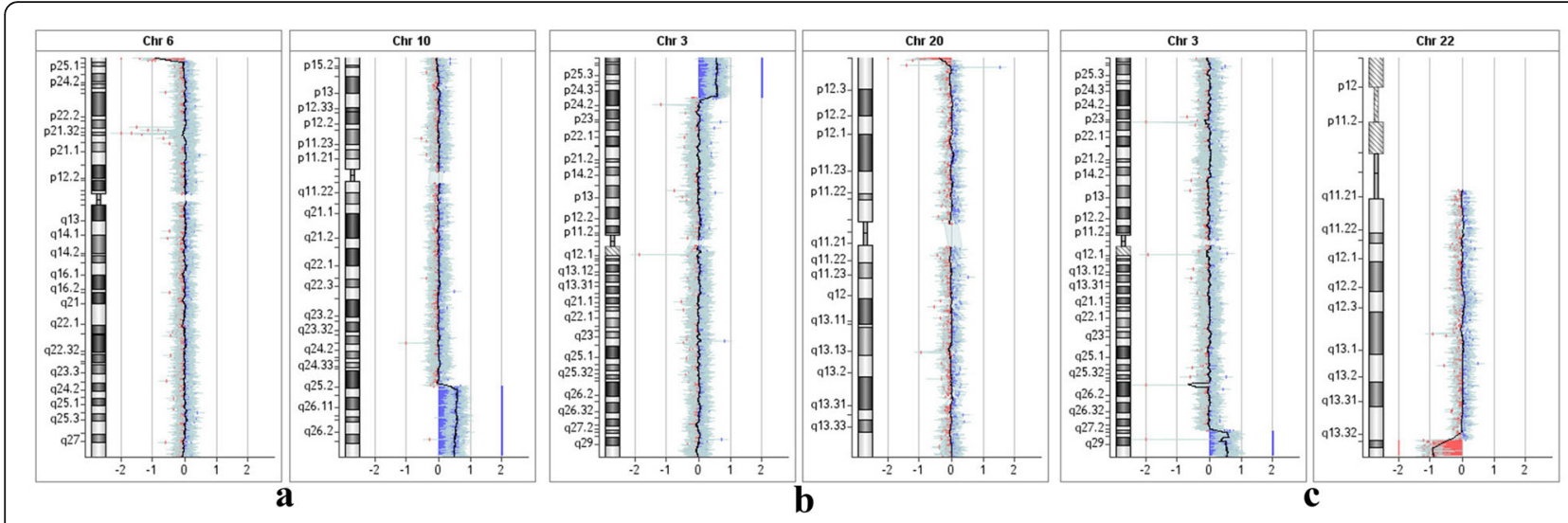

Fig. 3 Array-CGH analysis showed telomeric rearrangements on two different chromosomes in four patients (a: patient 1; b: patient 2 and 3; c: patient 4). The log ratio was reported (log2 intensity of [Cy5 fluorochrome/Cy3 fluorochrome)] on the X-axis. Expected values were from -0.7 to -1 for a deletion (red color), 0 for normal (black line), and +0.5 to +1 for a duplication (blue color)

karyotyped. The report showed balanced translocation of $46, \mathrm{XX} / \mathrm{XY}, \mathrm{t}(3 ; 20)(\mathrm{p} 23 ; \mathrm{p} 13)$ in the father and grandmother. Their GTG-banding images were not available.

Array-CGH analysis was performed in two female cousins to further characterize the rearrangement. This analysis identified that two female cousins have same abnormality rearrangement with a $19.9 \mathrm{Mb}$ duplication at 3p24.3-p26.3 (chr3:93949-19992330) and 0.25 Mb deletion at 20p13 (chr20: 121521-373182) (Fig. 3b).

\section{Family 3}

In this family, the healthy and nonconsanguineous young couples experienced three pregnancies history. After one miscarriage, they had a baby girl (family3: II2) at term by cesarean section. The couples went to our institution for genetic consulting, when pregnancy again, because their 5 years old daughter showed delayed growth, intellectual disability and language barrier. The girl also had facial expression dementia, paratrichosis (long eyelashes, bushy eyebrows and hair), brachydactylic hand, hypoplasia of distal phalanges, single palmar crease bilaterally, and thumb flat abduction of $90^{\circ}$. She walked independent at 3 years of age, but presented with cerebellar ataxia and walking instability. The girl could not finish fine motor coordination. She was not able to express simple language, speak slowly and ambiguously, and could only call mom and dad. Neurological exam revealed muscular hypotonia, nerve reflex insensitivity. She suffered congenital patent ductus arteriosus which was surgically cured at 2 years old. The hearing and vision was normal. Prenatal ultrasonography examination for the new pregnancy showed that fetus had bilateral multiple choroid plexus cyst with a larger size $(3.3 * 3.3 \mathrm{~mm})$ on the right side. The diameter of right renal pelvis was $4.5 \mathrm{~mm}$. Thickening of the placenta and single umbilical artery was also present.

Karyotype analysis showed that the girl and fetus had same karyotyped 46, XX, der (22) t (3; 22) (q27; q13.3) (Fig. $2 \mathrm{f}$ and g). Their parents were also karyotyped with the report showing normal $46, \mathrm{XY}$ in the father, but abnormal 46, XX, t $(3 ; 22)$ (q27; q13.3) in the mother (Fig. 2h).

Array-CGH analysis on the peripheral blood DNA from the girl showed a $12.5 \mathrm{Mb}$ duplication at chromosome 3q27.2-q29 (chr3:185307872-197840339), and a $1.9 \mathrm{Mb}$ deletion at 22q13.2-q13.33 (chr22: 4928675951178264) (Fig. 3c).

\section{Discussion}

In this work, we report three families with balanced translocation. They all have imbalanced translocation offspring with delayed growth, intellectual disability and language barrier. The complex phenotypic manifestation of patients was contributed jointly by monosomy and trisomy of the two chromosomes. Generally, phenotypes associated with deletions are more severe than those associated with duplications. However, because the maximum tolerance in living organisms was different, it is very difficult to justify the predominant factors. By reviewing the published literatures, the prominent phenotypic features of these patients were not classified as some specific syndrome.

The same karyotype has been reported in one patient of India [8]. Conventional karyotype shows patient with $46, \mathrm{XY}$, der $(6) \mathrm{t}(6 ; 10)$ (p23; q24) pattern which is the same as patient 1 . However, genitalia malformation, malformed ears, atrial septal defect and so forth features of India patient were not found in the patient 1 . The lower limbs dysplasia was prominent in patient 1 , but not reported in India patient. The facial features were similar 
in the two patients. The different breakpoint may be one of the main reasons that lead to the distinguished characteristics. One patient with 10q25.1-10q26.3 duplication reported by Carter et al. [9] has craniofacial dysmorphia, such as depressed nasal bridge, high arched palate, low set ears and low anterior hairline were same as patient 1 , however, skeletal anomalies were present in this patient, including hip dysplasia and mild scoliosis, which were not found in patient 1 . Hand anomaly and wide space between the first and second toes (sandal gap) were found in India patient and Carter's patient, but was not found in patient 1 , foot eversion was only present in patient 1. Hearing loss was found in India patient and Carter's patient, while patient 1 with normal hearing. They all had delayed growth, Intellectual disability and language barrier. We summarized Table 1 for comparison of the clinical features of this patient with similar segmental duplication and/or deletion chromosome. The FGFR2 was localized in this segmental duplication and was reported to be associated with many syndromes [10]. FGFR2 is a member of the fibroblast growth factor receptor family and encodes a receptor tyrosine kinase important for osteogenesis. Patients with FGFR2 missense mutation were mainly manifested as craniofacial and limb abnormalities. Duplication of FGFR2 may be responsible for the craniofacial features and skeletal anomalies in the above patient. We summarized OMIM gene associated with phenotype localized in this duplicated segment 10q25.1-q26.3 (chr10:111770926135404523) (Additional file 1). SMC3 mutation have been reported in subjects with Cornelia de Lange syndrome 3 [11], and these patients presented with craniofacial dysmorphia and mental retardation. SFXN4 mutation was relevant to growth retardation, hypotonia, and speech delay [12]. BBIP1 and SHOC2 mutation can lead to mental retardation $[13,14]$. Delayed growth, language barrier and neurocognitive developmental impairment may be a result of duplication of these genes.

One 40-year-old female with 6p25.3 -p25.2 (chr6: 203,722 - 2,740,501) deletion [15], extensive white matter changes is the main clinical feature, normal cognition and intelligence. Patient 1 with 6p25.3 (chr6:170426-1106808) deletion contain 3 Refseq gene, only one OMIM gene (IRF4) was associated with Skin/hair/eye pigmentation. Patient 1 was only 3 years old have not presentation these symptoms. Therefore, duplication of 10q25.1-q26.3 was leading role in contribute to the clinical findings seen in patient 1 .

Partial trisomy $3 \mathrm{p}$ syndrome is characterized by multiple congenital abnormalities, delayed speech, intellectual deficiency and so forth [16]. The clinical manifestations are quite varied, depending on the amount of 3 p genomic content in the trisomic state.
Patient 2 and 3 with $19.9 \mathrm{Mb}$ (chr3:93949-19992330) duplication of the 3p24.3-p26.3, main clinical features are development delay, intellectual disability, language impairment and learning impairment. One 5 years old boy with pure 3p26.2-p24.1 duplication reported by Natera-de Benito et al. [17] and one 9 years old boy with pure 3p26.2-p25.3 duplication reported by Bittel et al. [18] share the above clinical malformations. Two genes located in the common segmental duplication of four patients, SUMF1 mutations result in defective posttranslational modification of sulfatases, and show association with mental retardation, neurological deterioration, hydrocephalus and so on [19]. Loss of function mutation in SETD5 was associated with mental retardation, intellectual disability, delayed speech and so forth [20]. Duplication of tow genes may be account for development delay and cognitive impairment. Interestingly, the clinical feature of round face with full cheeks was found in patient 2 and two boy patients reported by Natera-de Benito et al. and Bittel et al., and the 9 years old boy presented with central obesity. GHRL located in the common segmental duplication of four patients, was known to be associated with obesity [21]. For patient 2 and 3, we will be extraordinarily watchful the possible onset of obesity. It is worth noting that the clinical feature of hand/foot anomaly and genital malformation were not found in patient 2 and 3, however, two boy patients reported by Natera-de Benito et al. and Bittel et al. were presented with above clinical features.

There are reports of individuals with deletion at 20p13 [22-24], we found that the similarly clinical features of these patients are developmental delay and intellectual disability. Patient 2 and 3 with $0.25 \mathrm{Mb}$ (chr20: 121521373182 ) deletion of the 20p13, at this segmental deletion contain 10 Refseq genes, not found OMIM gene associated with phenotype, of which two candidate gene (SOX12 and NRSN2) was identified as nervous system expressing genes that may be associated with developmental delay [24].

The clinical manifestations of the $3 q$ syndrome include typical facial features, growth and mental retardation, and frequent congenital heart defects [25]. Patient 4 presented with congenital patent ductus arteriosus, whereas other patient showed ventricular septal defect [25]. Patient 4 had long eyelashes and bushy eyebrows, which was also found in other family with $3 \mathrm{q}$ duplication $[25,26]$. Patient 4 showed prominent cerebellar ataxia symptom, but the symptom was absence in other family with $3 q$ duplication [25-27]. The feature of hand/foot anomaly was found in Patient 4 and other patients [25-27]. TP63 located in the common segmental duplication of above patients, and was known to be associated with many syndromes. The clinical features of patient with TP63 mutation were major presented with hand/foot anomaly and ectodermal 
Table 1 The clinical features of patient with similar segmental duplication and/or deletion chromosome

\begin{tabular}{|c|c|c|c|c|c|c|c|c|c|c|c|c|c|c|c|}
\hline & Patient 1 & {$[8]$} & {$[9]$} & {$[15]$} & $\begin{array}{l}\text { Patient } \\
2\end{array}$ & $\begin{array}{l}\text { Patient } \\
3\end{array}$ & {$[16]$} & [17] & {$[22]$} & $\begin{array}{l}{[23]} \\
\text { patient } 2\end{array}$ & Patient 4 & {$[25]$} & [27] & {$[30]$} & {$[31]$} \\
\hline $\begin{array}{l}\text { Segmental duplication/ } \\
\text { deletion }\end{array}$ & $\begin{array}{l}\text { dup } \\
\text { 10q25.1- } \\
\text { 10q26.3; } \\
\text { del 6p25.3 }\end{array}$ & $\begin{array}{l}\text { dup } \\
\text { 10q24- } \\
\text { 10qter; } \\
\text { del 6p23- } \\
\text { 6pter }\end{array}$ & $\begin{array}{l}\text { dup } \\
10 \mathrm{q} 25.1- \\
10 \mathrm{q} 26.3^{\mathrm{a}}\end{array}$ & $\begin{array}{l}\text { del } \\
6 p 25.3 \\
-p 25.2^{b}\end{array}$ & $\begin{array}{l}\text { dup } \\
\text { 3p26.3- } \\
\text { p24.3; } \\
\text { del } \\
\text { 20p13 }\end{array}$ & $\begin{array}{l}\text { dup } \\
3 p 26.3- \\
24.3 ; \text { del } \\
20 p 13\end{array}$ & $\begin{array}{l}\text { dup } \\
3 p 26.2^{-} \\
\text {p24. }\end{array}$ & $\begin{array}{l}\text { dup } \\
3 p 26.2- \\
\text { p25.3 }\end{array}$ & $\begin{array}{l}\text { del } \\
20 p 13^{d}\end{array}$ & 20p13-pter & $\begin{array}{l}\text { dup 3q27.2- } \\
3 q 29 ; \\
\text { del } 22 q 13.32- \\
22 q 13.33\end{array}$ & $\begin{array}{l}\text { dup } \\
\text { 3q26.3- } \\
\text { qter }\end{array}$ & $\begin{array}{l}\text { dup } \\
\text { 3q27-qtere, } \\
\text { del4p16.3 }\end{array}$ & $\begin{array}{l}\text { del } \\
22 q 13.31- \\
\text { q13.339 }\end{array}$ & $\begin{array}{l}\text { del } \\
22 q 13.3^{h}\end{array}$ \\
\hline Sex & $\mathrm{F}$ & M & $\mathrm{F}$ & $\mathrm{F}$ & $\mathrm{F}$ & $\mathrm{F}$ & M & M & $\mathrm{F}$ & $\mathrm{F}$ & $\mathrm{F}$ & M & $\mathrm{F}$ & M & $\mathrm{F}$ \\
\hline Age at last follow up (years) & $3 y$ & $1 \mathrm{~m}$ & $7 y$ & $40 y$ & $9 y$ & $4 y$ & $5 y$ & $9 y$ & $9 y$ & $15 y$ & $5 y$ & $11 \mathrm{~m}$ & $4 y$ & $5 y$ & $14 y$ \\
\hline Development delay & + & + & + & - & + & + & + & + & + & + & + & + & + & + & + \\
\hline \multicolumn{16}{|l|}{ Craniofacial features } \\
\hline Ocular hypertelorism & - & + & - & - & + & - & + & - & - & - & - & - & + & - & - \\
\hline Epicanthic folds & - & + & + & - & - & - & - & - & - & - & - & - & + & + & - \\
\hline Depressed nasal bridge & + & + & + & - & + & - & + & - & - & - & - & Wide & Wide & - & - \\
\hline Anteverted nostrils & + & - & - & - & - & - & - & - & - & - & - & + & - & - & - \\
\hline Long philtrum & + & Broad & Flat & - & - & - & - & - & Flat & - & - & Prominent & + & - & - \\
\hline Carp-shaped mouth & + & + & - & - & - & - & - & - & - & - & - & - & - & - & - \\
\hline Thin upper lips & + & - & + & - & + & + & - & - & + & - & - & + & - & - & - \\
\hline High arched palate & + & + & + & - & - & - & - & - & + & + & - & - & - & - & - \\
\hline Micrognathia & + & + & - & - & - & - & - & - & - & - & - & + & - & - & - \\
\hline Low set ears & + & + & + & - & - & - & - & - & - & + & - & + & - & - & - \\
\hline Malformed ears & - & + & - & - & - & - & $\begin{array}{l}\text { prominent } \\
\text { ears }\end{array}$ & - & - & + & - & - & - & - & - \\
\hline Low anterior hairline & + & - & + & - & - & - & - & - & + & - & - & + & $\begin{array}{l}\text { high } \\
\text { frontal } \\
\text { hairline }\end{array}$ & - & - \\
\hline Long eyelashes & - & - & - & - & - & - & - & - & - & - & + & + & - & - & - \\
\hline Bushy eyebrows & - & - & - & - & - & - & - & - & - & - & + & + & - & - & - \\
\hline Facial expression anomaly & - & - & - & - & + & + & - & - & - & - & + & - & - & - & - \\
\hline Microcephaly & - & - & - & - & - & - & + & - & - & - & - & - & - & - & + \\
\hline \multicolumn{16}{|l|}{ Cognitive development } \\
\hline Intellectual disability & + & + & + & - & + & + & $+($ mild $)$ & + & + & + & + & + & + & + & + \\
\hline Language impairment & + & + & + & - & + & + & + & + & - & - & + & N.A & + & + & + \\
\hline Learning impairment & + & N.A & + & - & + & + & + & + & + & + & + & N.A & N.A & N.A & N.A \\
\hline Heart defect & - & + & - & - & - & - & - & - & - & - & + & + & - & - & - \\
\hline Hearing loss & - & + & + & + & - & - & - & - & - & - & - & - & - & - & - \\
\hline
\end{tabular}


Table 1 The clinical features of patient with similar segmental duplication and/or deletion chromosome (Continued)

\begin{tabular}{|c|c|c|c|c|c|c|c|c|c|c|c|c|c|c|c|}
\hline \multicolumn{16}{|l|}{ Hand and foot } \\
\hline Hand anomaly & - & + & + & + & - & - & + & + & + & + & + & + & + & + & - \\
\hline Foot anomaly & + & + & + & - & - & - & + & - & + & - & - & + & - & - & - \\
\hline Single palmar crease & - & + & - & - & - & - & + & - & - & - & + & - & - & - & - \\
\hline \multicolumn{16}{|l|}{ Skeletal anomalies } \\
\hline Limbs & + & - & - & - & - & - & - & - & - & - & - & - & - & - & - \\
\hline Scoliosis & - & - & + & - & - & - & - & - & - & - & - & - & - & - & - \\
\hline Hip dysplasia & - & - & + & - & - & - & - & - & - & - & - & + & - & - & - \\
\hline \multicolumn{16}{|l|}{ Other } \\
\hline Muscular hypotonia & + & - & + & - & - & - & + & - & - & - & + & - & + & + & + \\
\hline Cerebellar ataxia & - & - & - & - & - & - & - & - & - & - & + & - & - & - & - \\
\hline Genital malformation & - & + & - & - & - & - & + & + & - & - & - & - & - & - & - \\
\hline Short neck & + & + & + & - & - & - & + & - & + & - & - & + & - & - & - \\
\hline Epilepsy & - & - & - & - & - & - & + & - & - & + & - & - & - & + & + \\
\hline $\begin{array}{l}\text { Round face with full } \\
\text { cheeks }\end{array}$ & - & - & - & - & + & - & + & + & - & - & - & - & - & - & - \\
\hline Central obesity & - & - & - & - & - & - & - & + & - & - & - & - & - & - & - \\
\hline
\end{tabular}

$F$ female, $M$ male, $y$ years, $m$ month, + presence of trait, - absence of trait, N.A not available, a: chr 10: 108 299 681-133 745 613, b: chr6: 203,722 - 2,740,501, c: chr3:3943808-29668053, d: chr20:1-1150000, e: chr3:183097052198295559, f: chr4:1-769191, g: chr22:46,204,739-51,178,264, h: chr22:49,389,829-51,178,264 
dysplasia. TP63 duplication may be contributed to hand/ foot anomaly of these patients. Development delay and cognitive impairment were also found in Patient 4 and other patients [25-27]. Interestingly, the clinical feature of cerebellar ataxia was only found in patient 4 . Mutation in KIAA0226 causes spinocerebellar ataxia [28] with patients presenting progressive incoordination of gait and poor coordination of hands, speech and eye movements, and cerebellar ataxia in early childhood and delayed motor development, as well as dysarthria and hyporeflexia. KIAA0226 may be a candidate gene for ataxia of patient 4 .

The 22q13.3 deletion syndrome, also known as Phelan-McDermid syndrome, this syndrome is characterized by neurological deficits which include global developmental delay, moderate to severe intellectual impairment, absent or severely delayed speech, and neonatal hypotonia. In addition, more than $50 \%$ of patients show autism or autistic-like behavior, and therefore it can be classified as a syndromic form of autism spectrum disorders (ASD) [29], some patients also have seizure manifestations [30, 31], but patient 4 absence of autism and seizure manifestations, cerebellar ataxia is the prominent characteristic different from other patient with the deletion of 22q13.3 [30, 31]. Development delay and cognitive impairment were common features of patient 4 and other patients $[30,31]$. SHANK3 located in the segmental deletion, the SHANK3 mRNA is localized to proximal and distal dendrites, and is highly expressed the hippocampus, cerebellar granular cells, caudate putamen and thalamic nuclei. It is a key part of normal neuron morphology and connectivity, and play an important role in synaptic formation and function, promote synaptic plasticity, and is critical for learning and memory [32]. Haploinsufficiency of SHANK3 may be contributed to the development delay and cognitive impairment. ARSA encodes the lysosomal enzyme arylsulfatase $\mathrm{A}$, mutation in this gene was reported in metachromatic leukodystrophy, characterized by progressive demyelination, gait disturbances, ataxias, optical atrophy, dementia, seizures, and spastic tetraparesis [33]. ARSA may be a candidate gene for ataxia of patient 4 .

\section{Conclusion}

The monosomy and trisomy of the two chromosomes lead to complex phenotypic manifestation of patients. These genes (Additional file 1) located in the region of rearrangement chromosome might promote abnormal clinical features of patients. We speculate that other genes may also be involved and multiple factors may play important role in the development of the abnormal features observed in our patients.

\section{Consent}

Written informed consent was obtained from patient's parents.

\section{Additional file}

Additional file 1: The OMIM gene associated with phenotype localized in the duplicated and deletion segment of four patients. (XLSX $20 \mathrm{~kb}$ )

\section{Competing interests}

The authors declare that they have no competing interests.

\section{Authors' contributions}

$\mathrm{H}-\mathrm{YL}$ designed the study and subject recruitment. DW, TL, JH and H-DW performed DNA extraction, array-CGH analysis and interpretation of the data. TW, L-JG and F-FH performed GTG-banding karyotype analysis. H-YL, Q-NG, YW, R-LW, and Y-TW participated in disease diagnose. The manuscript was drafted by $\mathrm{H}-\mathrm{YL}$ and $\mathrm{JH}$, all authors contributed to the final draft. All authors read and approved the final manuscript.

\section{Acknowledgement}

We thank our patients and their family member participation in this study.

\section{Funding}

This study is supported in part by the Young Scientists Foundation of China (NO. 8501336), Foundation and Cutting-edge Research Projects of Henan Province Science and Technology Department (No. 122300410400), Oversea Training Projects for medical academic leaders of Henan Province (No. 2014089), Medical Science and Technology research projects of Henan Provincial Health Bureau (No. 201403180), Scientific and Technological projects of the Technology Bureau of Jinshui District (No. 38).

\section{Author details}

'Department of Medical Genetics Institute, People's Hospital of Zhengzhou University (Henan Provincial People's Hospital), Zhengzhou 450003, Henan, China. ${ }^{2}$ Department of Gynaecology and Obstetrics, People's Hospital of Zhengzhou University (Henan Provincial People's Hospital), Zhengzhou 450003, Henan, China. ${ }^{3}$ Department of Ultrasonography, People's Hospital of Zhengzhou University (Henan Provincial People's Hospital), Zhengzhou 450003, Henan, China.

Received: 20 November 2015 Accepted: 12 April 2016

Published online: 19 April 2016

\section{References}

1. Zhang HG, Wang RX, Li LL, Sun WT, Zhang HY, Liu RZ. Male carriers of balanced reciprocal translocations in Northeast China: sperm count, reproductive performance, and genetic counseling. Genet Mol Res. 2015;14(4):18792-8.

2. Dijkhuizen $T$, van Essen $T$, van der Vlies $P$, Verheij JB, Sikkema-Raddatz $B$, van der Veen $\mathrm{AY}$, et al. FISH and array-CGH analysis of a complex chromosome 3 aberration suggests that loss of CNTN4 and CRBN contributes to mental retardation in 3pter deletions. Am J Med Genet A. 2006;140(22):2482-7.

3. Kara M, Sen A, Cetin ES, Kargun K. Chromosomal translocation t (10; 19) (q11.2;q13.4) in an infertile male. Eurasian J Med. 2014;46(3):220-3.

4. Manvelyan M, Schreyer I, Höls-Herpertz I, Köhler S, Niemann R, Hehr U, Belitz $B$, et al. Forty-eight new cases with infertility due to balanced chromosomal rearrangements: detailed molecular cytogenetic analysis of the 90 involved breakpoints. Int J Mol Med. 2007;19(6):855-64.

5. Stephenson MD, Sierra S. Reproductive outcomes in recurrent pregnancy loss associated with a parental carrier of a structural chromosome rearrangement. Hum Reprod. 2006;21(4):1076-82.

6. Kochhar PK, Ghosh P. Reproductive outcome of couples with recurrent miscarriage and balanced chromosomal abnormalities. J Obstet Gynaecol Res. 2013;39(1):113-20.

7. Goddijn M, Leschot NJ. Genetic aspects of miscarriage. Baillieres Best Pract Res Clin Obstet Gynaecol. 2000;14(5):855-65.

8. Ganguly BB, Kadam V, Kadam NN. Clinical expression of an inherited unbalanced translocation in chromosome 6. Case Rep Genet. 2011;2011: 396450. doi:10.1155/2011/396450. 
9. Carter MT, Dyack S, Richer J. Distal trisomy $10 \mathrm{q}$ syndrome: phenotypic features in a child with inverted duplicated 10q25.1-q26.3. Clin Dysmorphol. 2010;19(3):140-5.

10. Ibrahimi OA, Zhang F, Eliseenkova AV, Itoh N, Linhardt RJ, Mohammadi M. Biochemical analysis of pathogenic ligand-dependent FGFR2 mutations suggests distinct pathophysiological mechanisms for craniofacial and limb abnormalities. Hum Mol Genet. 2004;13(19):2313-24.

11. Deardorff MA, Kaur M, Yaeger D, Rampuria A, Korolev S, Pie J, et al. Mutations in cohesin complex members SMC3 and SMC1A cause a mild variant of cornelia de Lange syndrome with predominant mental retardation. Am J Hum Genet. 2007; 80(3):485-94.

12. Hildick-Smith GJ, Cooney JD, Garone C, Kremer LS, Haack TB, Thon JN, et al. Macrocytic anemia and mitochondriopathy resulting from a defect in sideroflexin 4. Am J Hum Genet. 2013;93(5):906-14.

13. Scheidecker S, Etard C, Pierce NW, Geoffroy V, Schaefer E, Muller J, et al. Exome sequencing of Bardet-Biedl syndrome patient identifies a null mutation in the BBSome subunit BBIP1 (BBS18). J Med Genet. 2014;51(2):132-6.

14. Cordeddu V, Di Schiavi E, Pennacchio LA, Ma'ayan A, Sarkozy A, Fodale V, et al. Mutation of $\mathrm{SHOC2}$ promotes aberrant protein $\mathrm{N}$-myristoylation and causes Noonan-like syndrome with loose anagen hair. Nat Genet. 2009;41(9):1022-6.

15. Vernon HJ, Bytyci Telegrafi A, Batista D, Owegi M, Leigh R. 6p25 microdeletion: white matter abnormalities in an adult patient. Am J Med Genet A. 2013;161A(7):1686-9.

16. Rodovalho-Doriqui MJ, Freitas PL, Pinho JD, Cavalli LR, Pereira SR. 3p partial trisomy and $13 q$ partial monosomy with congenital malformations and psychomotor developmental delay. Genet Mol Res. 2013;12(3):2562-6.

17. Natera-de Benito D, García-Pérez MA, Martínez-Granero MÁ, Izquierdo-López L. A patient with a duplication of chromosome 3p (p24.1p26.2): a comparison with other partial 3p trisomies. Am J Med Genet A. 2014;164A(2):548-50.

18. Bittel DC, Kibiryeva N, Dasouki M, Knoll JH, Butler MG. A 9-year-old male with a duplication of chromosome 3p25.3p26.2: clinical report and gene expression analysis. Am J Med Genet A. 2006;140(6):573-9.

19. Schlotawa L, Ennemann EC, Radhakrishnan K, Schmidt B, Chakrapani A, Christen $\mathrm{HJ}$, et al. SUMF1 mutations affecting stability and activity of formylglycine generating enzyme predict clinical outcome in multiple sulfatase deficiency. Eur J Hum Genet. 2011;19(3):253-61.

20. Grozeva D, Carss K, Spasic-Boskovic O, Parker MJ, Archer H, Firth HV, et al. De novo loss-of-function mutations in SETD5, encoding a methyltransferase in a 3 p25 microdeletion syndrome critical region, cause intellectual disability. Am J Hum Genet. 2014;94(4):618-24

21. Wortley KE, del Rincon JP, Murray JD, Garcia K, lida K, Thorner MO, et al. Absence of ghrelin protects against early-onset obesity. J Clin Invest. 2005;115(12):3573-8.

22. Jezela-Stanek A, Kucharczyk M, Pelc M, Gutkowska A, Krajewska-Walasek M. 1.15 Mb microdeletion in chromosome band 20p13 associated with moderate developmental delay-additional case and data's review. Am J Med Genet A. 2013;161A(1):172-8.

23. McGill AK, Pastore MT, Herman GE, Alliman S, Rosenfeld JA, Weaver DD. A tale of two deletions: a report of two novel 20p13 -> pter deletions. Am J Med Genet A. 2010;152A(4):1000-7

24. An Y, Amr SS, Torres A, Weissman L, Raffalli P, Cox G, et al. SOX12 and NRSN2 are candidate genes for 20p13 subtelomeric deletions associated with developmental delay. Am J Med Genet B Neuropsychiatr Genet. 2013;162(8):832-40.

25. Faas BH, De Vries BB, Van Es-Van Gaal J, Merkx G, Draaisma JM, Smeets DF. A new case of dup (3q) syndrome due to a pure duplication of 3qter. Clin Genet. 2002:62(4):315-20.

26. Abreu-González M, García-Delgado C, Cervantes A, Aparicio-Onofre A, Guevara-Yáñez R, Sánchez-Urbina R, et al. Clinical, Cytogenetic, and Biochemical Analyses of a Family with a t(3;13)(q26.2;p11.2): Further Delineation of 3q Duplication Syndrome. Case Rep Genet. 2013;2013: 895259. doi:10.1155/2013/895259.

27. Grossmann V, Müller $D$, Müller W, Fresser F, Erdel M, Janecke $A R$, et al. "Essentially" pure trisomy 3q27 -> qter: further delineation of the partial trisomy 3q phenotype. Am J Med Genet A. 2009;149A(11):2522-6.

28. Assoum M, Salih MA, Drouot N, H'Mida-Ben Brahim D, Lagier-Tourenne C, AIDrees A, et al. Rundataxin, a novel protein with RUN and diacylglycerol binding domains, is mutant in a new recessive ataxia. Brain. 2010;133(Pt8):2439-47.

29. Phelan K, McDermid HE. The 22q13.3 Deletion Syndrome (Phelan-McDermid Syndrome). Mol Syndromol. 2012;2(3-5):186-201.

30. Ishikawa N, Kobayashi Y, Fujii Y, Yamamoto T, Kobayashi M. Late-onset epileptic spasms in a patient with 22q13.3 deletion syndrome. Brain Dev. 2016;38(1):109-12.
31. Figura MG, Coppola A, Bottitta M, Calabrese G, Grillo L, Luciano D, et al. Seizures and EEG pattern in the 22q13.3 deletion syndrome: clinical report of six Italian cases. Seizure. 2014;23(9):774-9.

32. Costales IL, Kolevzon A. Phelan-McDermid Syndrome and SHANK3: Implications for Treatment. Neurotherapeutics. 2015;12:620-30. doi:10.1007/s13311-015-0352-z.

33. Eng B, Nakamura LN, O'Reilly N, Schokman N, Nowaczyk MM, Krivit W, et al. Identification of nine novel arylsulfatase a (ARSA) gene mutations in patients with metachromatic leukodystrophy (MLD). Hum Mutat. 2003;22(5):418-9.

\section{Submit your next manuscript to BioMed Central and we will help you at every step:}

- We accept pre-submission inquiries

- Our selector tool helps you to find the most relevant journal

- We provide round the clock customer support

- Convenient online submission

- Thorough peer review

- Inclusion in PubMed and all major indexing services

- Maximum visibility for your research

Submit your manuscript at www.biomedcentral.com/submit
) Biomed Central 